\title{
Thermal Stability of Rolled Metastable Austenitic Stainless Steel 1.4307 Studied Using Positron Annihilation
}

\begin{abstract}
E. DRYZEK, M. SARNEK, and M. WRÓBEL
Positron annihilation spectroscopy (PAS) was used in the study of cumulative isochronal and isothermal annealing of rolled 1.4307 (EN) stainless steel (SS). Due to different rolling temperatures, the SS samples varied in the $\alpha^{\prime}$-martensite volume fraction from 0.09 to 0.91 . The measurements of positron annihilation characteristics, i.e., Doppler broadening (DB) of the annihilation line, showed a gradual annealing of vacancies in the temperature range between $200{ }^{\circ} \mathrm{C}$ and $400{ }^{\circ} \mathrm{C}$, which indicated the first stage of recovery. This first stage of recovery did not change the microhardness. In the temperature range from $475{ }^{\circ} \mathrm{C}$ to $600{ }^{\circ} \mathrm{C}$, a decrease in the microhardness and generation of new open volume defects accompanying the reversion of $\alpha^{\prime}$-martensite to austenite was observed. The amount of these defects correlated with the initial $\alpha^{\prime}$-martensite volume fraction. Their formation could be related to the volume contraction occurring during bcc/fcc transformation. The different chemical surroundings suggested that the positron trapping defects were associated with the metal carbide precipitates.
\end{abstract}

https://doi.org/10.1007/s11661-018-5053-x

(C) The Author(s) 2018

\section{INTRODUCTION}

Austenitic stainless steel (SS) is plastically deformed by a slip of dissociated dislocations because of low stacking fault energy (SFE). This effect produces hardening due to an increase in dislocation density (dislocation hardening), but also due to stacking faults and mechanical twins formation. ${ }^{[1,2]}$ However, a large part of strain hardening results from the creation of deformation-induced martensite (DIM) caused by thermodynamic metastability of austenite at, or just below, room temperature (RT) ${ }^{[3,4]}$ Annealing of cold-worked austenitic SS causes martensite reversion along with other phenomena including recovery, recrystallization, and carbide precipitation. ${ }^{[5,6]}$ Several experimental techniques, such as microscopic examination, X-ray diffraction (XRD), and magnetic or mechanical properties measurements, have been applied to study the properties of cold-worked austenitic SS during annealing. However, new methods for fast industrial applications are

E. DRYZEK is with the Institute of Nuclear Physics, Polish Academy of Sciences, 31342 Kraków, Poland. Contact email: ewa.dryzek@ifj.edu.pl M. SARNEK is with the Cracow University of Economics, 31-510 Kraków, Poland. M. WRÓBEL is with the AGH University of Science and Technology, 30-059 Kraków, Poland. Manuscript submitted March 28, 2018.

Article published online December 7, 2018 investigated. Positron annihilation spectroscopy (PAS) offers further potential for such applications.

PAS is a well-known experimental method used for studying defects in crystalline solids such as metals, alloys, and semiconductors. ${ }^{[7]}$ It is based on the following facts. When an energetic positron is implanted into a solid, it rapidly loses its energy, reaching thermal energy. After a short period of random walk, it annihilates with an electron, usually producing two high-energy annihilation photons. Their momentum carries information on the annihilation site's surroundings. During their random walk, positrons can be trapped in crystal lattice imperfections, such as open volume defects, where the electron density is reduced in comparison to the perfect lattice. This causes changes of usually measured parameters: narrowing of the Doppler-broadened annihilation line and an increase in the positron lifetime. Vacancies, vacancy clusters, some grain boundaries, and interfaces, as well as the second-phase precipitations, can act as positron traps. Dislocations are also expected to provide trapping sites; however, they are rather shallow traps. The sensitivity of positron lifetime and width of the annihilation line form the basis for the two main PAS techniques, i.e., positron annihilation lifetime spectroscopy and doppler broadening (DB) of annihilation line to defect studies.

Our previous studies showed that reverse transformation of DIM in metastable austenitic SS is easily detected using PAS. The method revealed two processes that take place during annealing of compression-deformed SS samples that contain DIM: migration and 
sinking of vacancies and creation of additional lattice defects. ${ }^{[8,9]}$ A significant change in the shape of the annihilation line was observed for the temperature range of $\alpha^{\prime}$-martensite reversions in the tension-deformed samples. The PL measurements indicated the presence of large vacancy clusters consisting of six to nine vacancies, which occurred at the interface between the austenite and $\alpha^{\prime}$ martensite phases due to the volume contraction accompanying the bcc/fcc transformation. ${ }^{[10]}$ We believe that the nucleation and growth of metal carbide precipitates, mainly $\mathrm{M}_{23} \mathrm{C}_{6}$ type, could also provide positron trapping sites in the matrix-precipitate interfaces. ${ }^{[11]}$

The purpose of the present study was to investigate the use of the PAS technique to study 1.4307 (EN) SS samples deformed by rolling at different temperatures and to a much higher degree of deformation compared to our previous studies. This allowed us to examine how the amount of $\alpha^{\prime}$-martensite influenced defect formation during reverse transformation. We applied two different annealing methods: isochronal annealing and isothermal annealing at $550{ }^{\circ} \mathrm{C}$ and $650{ }^{\circ} \mathrm{C}$. The temperatures of isothermal annealing were chosen to take into account the precipitation of $\mathrm{M}_{23} \mathrm{C}_{6}$ carbides leading to intergranular corrosion sensitivity of steel. ${ }^{[12]}$ Other techniques, such as XRD, microhardness, and magnetic properties measurements, were used to supplement the PAS studies.

\section{MATERIALS AND METHODS}

\section{A. Sample Preparation}

The measurements were carried out on the commercial 1.4307 (EN) SS, which is equivalent to AISI Grade 304L. Its chemical composition is given in Table I. SS samples of size $3 \times 15 \times 100 \mathrm{~mm}^{3}$ were subjected to 30-minute solution annealing at $1100{ }^{\circ} \mathrm{C}$ followed by cooling in air. After the heat treatment, the surfaces of the samples were etched with the use of hydrochloric acid and nitric acid water solution to obtain a clean surface.

To obtain a different amount of DIM, the samples were deformed at different temperatures. They were rolled one after another with the same settings of the mill. Multiple passes were used to obtain a final deformation. Before and immediately after each pass, sample A was immersed in liquid nitrogen (LN) for at least 15 minutes. Sample B was deformed at RT. Sample $\mathrm{C}$ was deformed at $200{ }^{\circ} \mathrm{C}$ and was heated in an air circulating furnace. The $\mathrm{LN}$ container and the furnace were located right next to the mill, and only a few seconds were required to transfer the samples to the mill. Due to the difference in deformation temperatures, the strain hardening was different and the final deformation $\varepsilon$ varied slightly, as is shown in Table II.

Three sets of specimens of $15 \mathrm{~mm}$ in length were cut from the rolled samples A, B, and C. Each set was used for positron annihilation measurements, which required two identical specimens, whereas additional specimens were used for XRD and microhardness measurements. Before the examination, the surface layer of all the samples was removed by electropolishing or etching to remove the possible effect of the preparation (i.e., cutting, polishing). The specimens were polished electrolytically according to Struers' recommendation (A2 electrolyte, approximately $35 \mathrm{~V})$. The samples that were used for optical microscopy (OM) observations were etched in an electrolyte consisting of 60 pet nitric acid and 40 pet $\mathrm{H}_{2} \mathrm{O}$ to reveal the general microstructure. To reveal the DIM, electropolishing was followed by etching in a mixture of $0.15 \mathrm{~g}$ of $\mathrm{Na}_{2} \mathrm{~S}_{2} \mathrm{O}_{5}$ solved in $100 \mathrm{~mL}$ of distilled water and $10 \mathrm{~mL}$ of $\mathrm{HCl}$ solved in $100 \mathrm{~mL}$ of water. ${ }^{[13]}$

The specimens from the first set were subjected to cumulative isochronal annealing in the flow of nitrogen gas for 1 hour at temperatures in the range of $50{ }^{\circ} \mathrm{C}$ to $825{ }^{\circ} \mathrm{C}$ with $25^{\circ} \mathrm{C}$ interval. The remaining two sets of samples were subjected to isothermal annealing at $550{ }^{\circ} \mathrm{C}$ and $650{ }^{\circ} \mathrm{C}$, respectively. After annealing, the samples were etched to remove the oxidized surface layer. Finally, the samples were measured using the PAS, XRD, and microhardness techniques.

\section{B. Magnetic Properties Measurements}

The response of the deformed samples to the magnetic field was determined using an MPMS SQUID magnetometer. Magnetization curves up to $10 \mathrm{kOe}$ were measured at RT for additional samples of dimensions approximately $3 \times 2 \times 1 \mathrm{~mm}^{3}$, cut using the low-speed diamond wheel saw, and etched to remove the layer deformed by cutting. The volume fraction of $\alpha^{\prime}$-martensite $f_{\alpha^{\prime}}$ induced by plastic deformation was determined using the formula proposed by Mangonon and Thomas: ${ }^{[3]}$

$$
f_{\alpha^{\prime}}=\sigma_{s} / 160.4
$$

where $\sigma_{s}$ is the specific saturation magnetization per unit mass.

\section{XRD, Microhardness, and Microstructure Studies}

The samples' phase composition was tested using the XRD measurements carried out using the Philips X-Pert diffractometer with $\mathrm{Cu} K_{\alpha}$ radiation. The structural analyses using $\mathrm{OM}$ and scanning electron microscopy (SEM) were performed to reveal a general microstructure and DIM. Optical micrographs were recorded with the Zeiss Axio Imager M1m. The SEM observations were carried out using FEI Inspect S50. Microhardness studies were performed using a Wilson Hardness ${ }^{\mathrm{TM}}$ TUKON $^{\mathrm{TM}} *$

*Wilson Hardness and TUKON are a registered trademarks of Illinois Tool Works Inc. (ITW), Glenview, IL.

2500 (Instron ITW) device. The measurements were done using the Knoop indenter at normal load of 100 g. For each measurement, two sets of indentations for the mutually perpendicular position of the indenter's longest axis were made (from 10 to 16 indentations for one set). The results were recalculated to the Vickers standard units. All recommendations of the ISO 4545 standard were respected. ${ }^{[14]}$ 
Table I. Steel Composition (Weight Percent)

\begin{tabular}{cccccccccccc}
\hline $\mathrm{Cr}$ & $\mathrm{Ni}$ & $\mathrm{Mn}$ & $\mathrm{Si}$ & $\mathrm{Cu}$ & $\mathrm{Mo}$ & $\mathrm{V}$ & $\mathrm{P}$ & $\mathrm{S}$ & $\mathrm{C}$ & $\mathrm{N}$ & $\mathrm{Fe}$ \\
\hline 18.00 & 8.10 & 1.46 & 0.40 & 0.26 & 0.10 & 0.09 & 0.033 & 0.005 & 0.023 & 0.05 & balance \\
\hline
\end{tabular}

Table II. Deformation Conditions, Saturation Magnetization per Unit Mass $\sigma_{s}$, and Volume Fraction of $\alpha^{\prime}$ Martensite $f_{\alpha^{\prime}}$ Calculated from the $\sigma_{s}$ Value Using Eq. [1]

\begin{tabular}{lccrr}
\hline Sample & Deformation $\varepsilon(\mathrm{pct})$ & Deformation Temperature & \multicolumn{1}{c}{$\sigma_{s}(\mathrm{emu} / \mathrm{g})$} & $f_{\alpha^{\prime}}$ \\
\hline A & 56 & LN & $145.8 \pm 2.1$ & $0.91 \pm 0.01$ \\
B & 60 & RT & $102.0 \pm 0.5$ & $0.64 \pm 0.01$ \\
C & 62 & $200{ }^{\circ} \mathrm{C}$ & $14.7 \pm 0.1$ & $0.09 \pm 0.01$ \\
\hline \multicolumn{2}{l}{ RT-room temperature; LN-after immersion in liquid nitrogen. } & \\
\hline
\end{tabular}

\section{PAS Measurements}

PAS measurements were carried out using the ${ }^{22} \mathrm{Na}$ positron source encapsulated in 7 - $\mu$ m-thick Kapton foil. The DB of the $511 \mathrm{keV}$ annihilation line was measured using a coaxial high-purity germanium (HPGe) detector with a $1.4 \mathrm{keV}$ energy resolution at the full width at half maximum (FWHM) interpolated at $511 \mathrm{keV}$. The measurements were performed at RT after each annealing step. To characterize the annihilation line shape, we used the so-called $S$ and $W_{\text {r }}$ parameters. The $S$ parameter is defined as the ratio of the area under the fixed central part of the annihilation line, i.e., the energy range $511.0 \pm 1.1 \mathrm{keV}$, to the area under the entire peak. The $S$ parameter is sensitive to the annihilation of positrons with low momentum electrons, which are present in open volume defects. The wing parameter $W_{\mathrm{r}}$ value is the ratio of the area under the right wing of the annihilation line to the area under the entire annihilation line. The $W_{\mathrm{r}}$ parameter is mainly influenced by the positron annihilation with core electrons, which have higher momenta. It is also affected by the chemical surroundings of the annihilation site. The $W_{\mathrm{r}}$-parameter energy range was between 514.9 and $516.9 \mathrm{keV}$. Information on the defect type changes was derived from the correlation between the $S$ and $W_{\mathrm{r}}$ parameters. The values of the $S$ and $W_{\mathrm{r}}$ parameters were evaluated using the SP-11 code. ${ }^{[15]}$

The positron lifetime (PL) measurements were performed at RT for the as-deformed samples and the samples annealed at selected temperatures. The PL spectra of more than $1.5 \times 10^{6}$ counts were collected using the so-called fast-fast spectrometer with $\mathrm{BaF}_{2}$ scintillators. The time resolution of the spectrometer was equal to $270 \mathrm{ps}$ (FWHM). All the obtained spectra were analyzed using the LT-code subtracting contribution of the positron source and background. ${ }^{[16]}$

\section{RESULTS}

\section{A. The Initial As-Deformed State}

Figure 1 shows the XRD patterns for samples A, B, and $\mathrm{C}$ after rolling. For sample $\mathrm{C}$ deformed at $200{ }^{\circ} \mathrm{C}$,

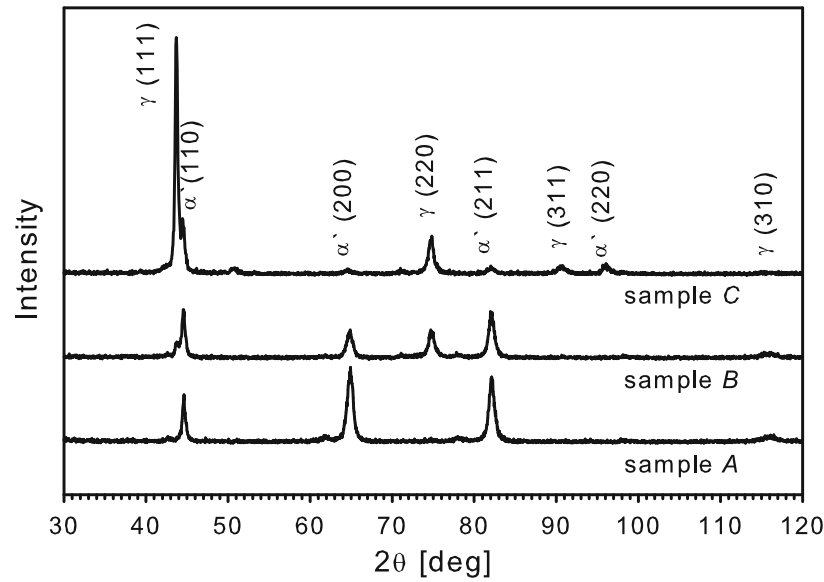

Fig. 1-XRD patterns for as-deformed samples A, B, and C rolled at different temperatures.

peaks from the $\gamma$ phase are predominant in comparison to two other samples deformed at lower temperatures, i.e., samples A and B deformed close to the LN and RT, respectively. For the latter, peaks originating from $\alpha^{\prime}$-martensite are mainly visible.

Figure 2 depicts magnetization curves measured at RT. The values of the specific saturation magnetization per unit mass $\sigma_{s}$ and the volume fraction of $\alpha^{\prime}$-martensite $f_{\alpha^{\prime}}$ determined using Eq. [1] are given in Table II. The amount of DIM determined by the magnetization measurements was confirmed by the image analysis of the etched specimen microstructure. An exemplary result shown in Figure 3 refers to sample B rolled at $\mathrm{RT}$, for which the amount of $\alpha^{\prime}$-martensite was determined at $0.64 \pm 0.01$. Grain boundaries and typical morphology of the strain-induced martensite can be seen in the microstructure examined both by SEM and OM (Figures 3(a) and (b), respectively).

\section{B. Isochronal Annealing}

Figure 4 presents the results of the microhardness and DB measurements for isochronal annealing for samples $\mathrm{A}, \mathrm{B}$, and $\mathrm{C}$. The Vickers microhardness values as a function of the annealing temperature are shown in Figure 4(a). Sample A, with the highest volume fraction 
of $\alpha^{\prime}$ martensite, shows the highest initial value of microhardness, $481 \pm 17 \mathrm{HV}$. The microhardness value of sample B is slightly lower, $462 \pm 14 \mathrm{HV}$. Sample C, with the lowest volume fraction of $\alpha^{\prime}$-martensite, has the lowest value, $421 \pm 30 \mathrm{HV}$. Although the differences in the initial microhardness values are small, the dependence on the $\alpha^{\prime}$-martensite amount is clear: the higher the $\alpha^{\prime}$-martensite volume fraction, the higher the microhardness. The microhardness does not change significantly up to an annealing temperature of $425^{\circ} \mathrm{C}$. For samples $\mathrm{A}$ and $\mathrm{B}$ at a higher amount of $\alpha^{\prime}$-martensite, a slight increase is observed at a temperature of $475^{\circ} \mathrm{C}$. The softening of the material for samples $\mathrm{A}$ and $\mathrm{B}$ is seen for annealing temperatures higher than $475^{\circ} \mathrm{C}$. For sample $\mathrm{C}$, the microhardness shows a decrease starting above $700{ }^{\circ} \mathrm{C}$, where the values for all three samples are close to each other. The inserts show optical micrographs of the microstructure of sample $\mathrm{C}$ : rolled and after annealing at $550{ }^{\circ} \mathrm{C}$ and $750{ }^{\circ} \mathrm{C}$, respectively. After the entire annealing cycle, the values of the microhardness are higher than those of the sample after solution annealing at $1100{ }^{\circ} \mathrm{C}$ and cooling in the air at approximately $190 \pm 10 \mathrm{HV}$.

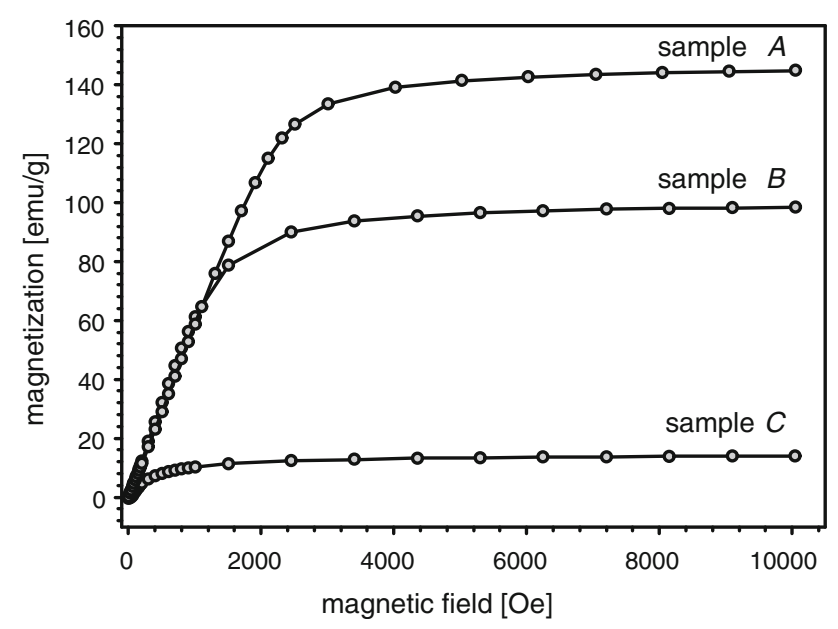

Fig. 2-Magnetization curves for samples A, B, and C deformed by tension at different temperatures.
Figures 4(b) and (c) show the $S$ - and $W_{\mathrm{r} \text {-parameter }}$ values as a function of the annealing temperature. Initially, for the as-deformed samples, a higher deformation corresponds to a higher $S$-parameter value. The $S$-parameter decreases only slightly with a temperature increase up to $175^{\circ} \mathrm{C}$. The most pronounced decrease is clearly visible for a temperature in the range from $200{ }^{\circ} \mathrm{C}$ to $425^{\circ} \mathrm{C}$ for sample $\mathrm{A}$ and from $200{ }^{\circ} \mathrm{C}$ to $450{ }^{\circ} \mathrm{C}$ for samples $\mathrm{B}$ and $\mathrm{C}$. This decrease indicates a disappearance of positron trapping defects; however, it is not accompanied by a reduction of microhardness according to Figure 4(a). This annealing temperature range is the first recovery stage consisting of the diffusion and sinking of vacancies generated during deformation. ${ }^{[17-19]}$ At $475^{\circ} \mathrm{C}$, the $S$ parameter increases rapidly for all three samples, is maintained at the same level in the temperature range from $475^{\circ} \mathrm{C}$ to $600{ }^{\circ} \mathrm{C}$, and then decreases until $825^{\circ} \mathrm{C}$. As mentioned previously, the initial values of the $S$ parameter are ordered by the degree of deformation, and from a temperature of $450{ }^{\circ} \mathrm{C}$, their order is reversed, which is congruous with the increasing $\alpha^{\prime}$ - martensite volume fraction (Table II). In spite of the significant differences in the $\alpha^{\prime}$ - martensite volume fraction in the as-deformed samples, the differences in the $S$-parameter values in all three samples in the temperature range from $475{ }^{\circ} \mathrm{C}$ to $600{ }^{\circ} \mathrm{C}$ are small. The $W_{\mathrm{r}}$-parameter dependences shown in Figure 4(c) are almost mirror images of the $S$-parameter dependences with respect to the temperature axis up to $425^{\circ} \mathrm{C}$ and then above $600{ }^{\circ} \mathrm{C}$. In the intermediate temperature region, there is a distinct dependence of the $W_{\mathrm{r}}$-parameter maximal values at $425^{\circ} \mathrm{C}$ and $450{ }^{\circ} \mathrm{C}$ on the $\alpha^{\prime}$-martensite fraction. The following decrease in the $W_{\mathrm{r}}$ parameter does not reflect the $S$-parameter dependence strictly.

Figure 5 depicts the $S-W_{\mathrm{r}}$ plots for the measured samples. The plots show a linear relationship for sample $\mathrm{C}$ within the entire temperature range. For samples $\mathrm{A}$ and $\mathrm{B}$, the linear relationship is observed from RT to $350{ }^{\circ} \mathrm{C}$, where a decrease in the $S$ parameter in Figure 4(b) is accompanied by an increase in the $W_{\mathrm{r}}$ parameter in Figure 4(c). A linear relationship for the $W_{\mathrm{r}}-S$ function indicates that the main type of positron trapping defects does not change, but only their
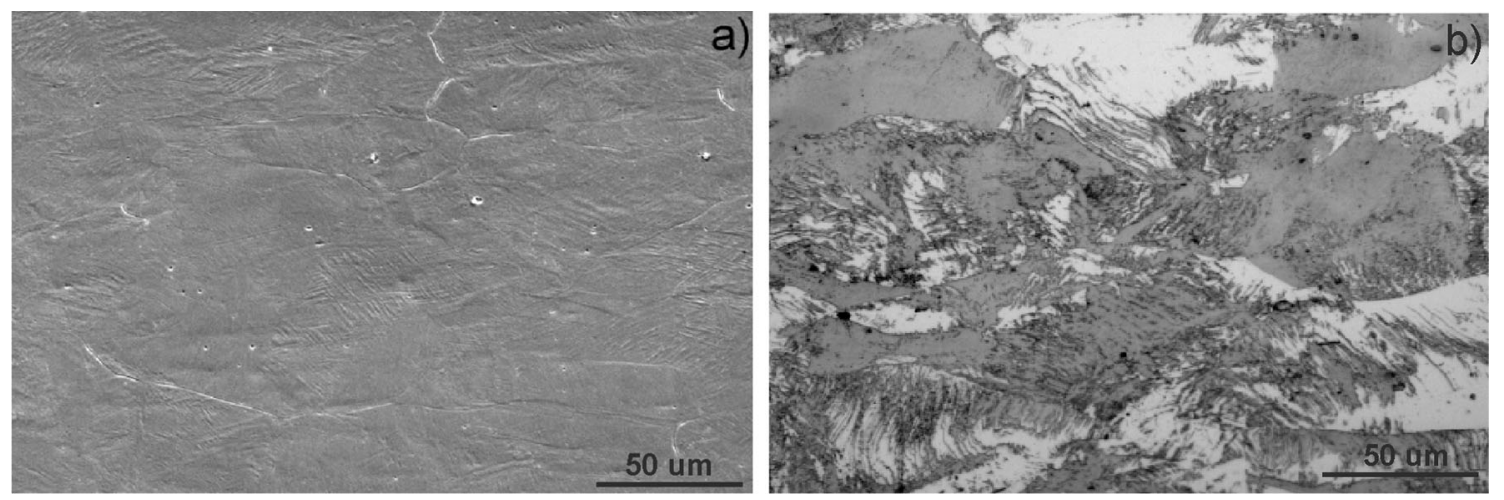

Fig. 3-Microstructure of sample B rolled at RT: (a) SEM of a slightly etched specimen and (b) DIM revealing etching OM. The rolling direction is parallel to the scale bar. 


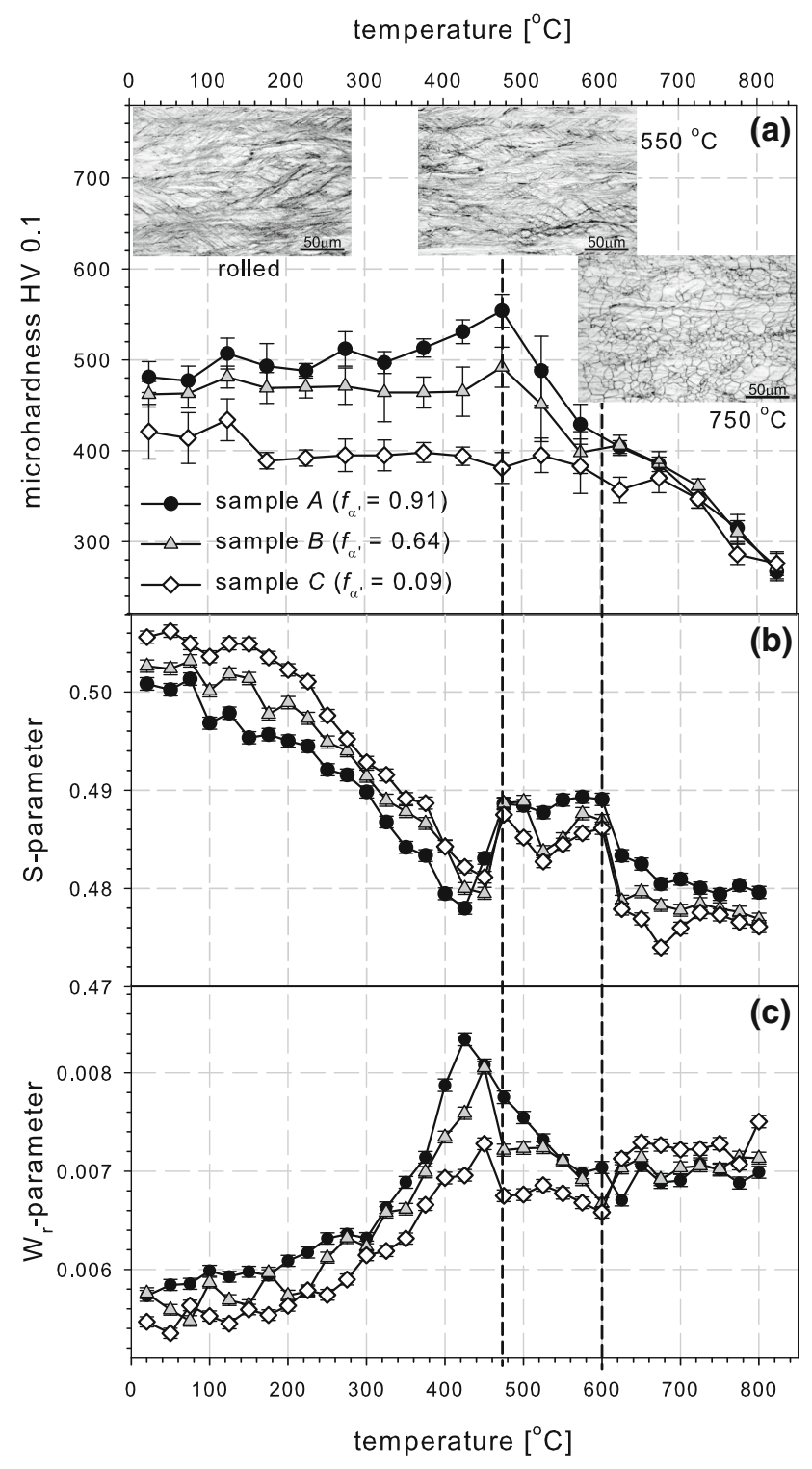

Fig. 4-Effect of 1-h isochronal annealing on (a) the microhardness and the values of the $(b) S$ - and $(c) W_{\mathrm{r}}$-annihilation line shape parameters, respectively, for samples $\mathrm{A}, \mathrm{B}$, and $\mathrm{C}$ rolled at different temperatures; $f_{\alpha^{\prime}}$ is the initial fraction of $\alpha^{\prime}$-martensite. The inserts show optical micrographs of the microstructure in the longitudinal sections of sample $\mathrm{C}$ rolled and after annealing at $550{ }^{\circ} \mathrm{C}$ and $750{ }^{\circ} \mathrm{C}$. The rolling direction is parallel to the scale bar.

concentration does. The slopes of the lines $-16.6 \pm 0.7$ and $-16.4 \pm 0.6$ for samples A and B, respectively, are the same within the experimental error. However, for the temperature range between $400{ }^{\circ} \mathrm{C}$ and $600{ }^{\circ} \mathrm{C}$, the points significantly diverge from the linear slope. This tendency starts at a relatively low annealing temperature, i.e., $375^{\circ} \mathrm{C}$, when the $S$ parameter still decreases. This behavior is most pronounced for sample A with the highest $\alpha^{\prime}$-martensite volume fraction (Figure 5(a)). The diverging points form a loop and return to a straight line. The loop is marked by line segments connecting the points for the increasing annealing temperatures in Figure 5. For sample C, divergence from a straight line is relatively small. The slope of the straight line fitted to all the points for sample $\mathrm{C}$ is equal to $-15.3 \pm 0.5$ and differs slightly from those for samples A and B, but the difference is still within the experimental error and can be caused by taking into account the points in the temperature region of the loop.

The results of the PL measurements for all three samples after annealing at selected temperatures are presented in Table III. Only one PL was resolved in all the spectra, and it can be treated as the mean PL, as discussed in Reference 10 . It can be seen that the changes of the PL for samples A and B reflect the dependence of the $S$ parameter on the annealing temperature, i.e., a decrease at $350{ }^{\circ} \mathrm{C}$ and then an increase at $500{ }^{\circ} \mathrm{C}$ followed by another decrease at $800{ }^{\circ} \mathrm{C}$. However, for sample $\mathrm{C}$, with the lowest amount of $\alpha^{\prime}$-martensite, the PL does not increase after annealing at $500{ }^{\circ} \mathrm{C}$.

\section{Isothermal Annealing}

The XRD patterns for the samples after annealing at $550{ }^{\circ} \mathrm{C}$ for $670 \mathrm{ks}$ are shown in Figure 6. Peaks $110_{\alpha^{\prime}}$, $20 \alpha_{\alpha^{\prime}}$, and $211_{\alpha^{\prime}}$ denote that even such long annealing did not cause a total $\alpha^{\prime}$ martensite reversion. Other visible peaks are also present, which can be caused by carbides, mainly $\mathrm{M}_{23} \mathrm{C}_{6}$. Carbide precipitation at these temperatures is typical of the investigated SS. ${ }^{[20]}$

The results of the microhardness and DB measurements for samples isothermally annealed at $650^{\circ} \mathrm{C}$ and $550{ }^{\circ} \mathrm{C}$ are depicted in Figure 7. Annealing at $650{ }^{\circ} \mathrm{C}$ for $51 \mathrm{ks}$ decreases the microhardness to about $200 \mathrm{HV}$, while annealing at $550{ }^{\circ} \mathrm{C}$ for $670 \mathrm{ks}$ results in values of 300 to $380 \mathrm{HV}$. For sample $\mathrm{C}$ annealed at $650{ }^{\circ} \mathrm{C}$, the $S$ parameter decreases in the entire time range. For samples A and B, the $S$ parameter slightly increases after annealing at $1.8 \mathrm{ks}$ and then decreases. This behavior causes a change in the sequence of the $S$-parameter values, as it takes place during isochronal annealing at temperatures higher than $500{ }^{\circ} \mathrm{C}$. After annealing for $51 \mathrm{ks}$ at $650{ }^{\circ} \mathrm{C}$, the $S$-parameter values are close to that obtained for the solution-treated sample annealed additionally for $3.6 \mathrm{ks}$ at $700{ }^{\circ} \mathrm{C}$ and cooled slowly with the furnace. The latter treatment allows us to remove thermally generated vacancies that remained in the sample as a result of relatively fast cooling in air from temperature $1100{ }^{\circ} \mathrm{C}$. Then the annealing at $650{ }^{\circ} \mathrm{C}$ for $51 \mathrm{ks}$ removes defects where positrons could potentially localize in all three samples. The $W_{\mathrm{r}}$-parameter dependences on the annealing temperature reflect those of the $S$ parameter.

For annealing at $550{ }^{\circ} \mathrm{C}$, there is a decrease in the $S$-parameter values after the first $1.8 \mathrm{ks}$. Similarly to annealing at $650{ }^{\circ} \mathrm{C}$, the $S$-parameter values change their sequence in comparison to the initial one. Then, the $S$ parameter slightly increases for all the samples, and after a slight decrease, it remains constant, not reaching the final value obtained for the samples annealed at $650{ }^{\circ} \mathrm{C}$. Even a long annealing at $550{ }^{\circ} \mathrm{C}$ does not remove sites where positrons are localized.

For the samples annealed at $650{ }^{\circ} \mathrm{C}$, a straight line can be fitted to all experimental points in the $S-W_{\text {r }}$ plot (Figure 8(a)). The slope of the line equal to 


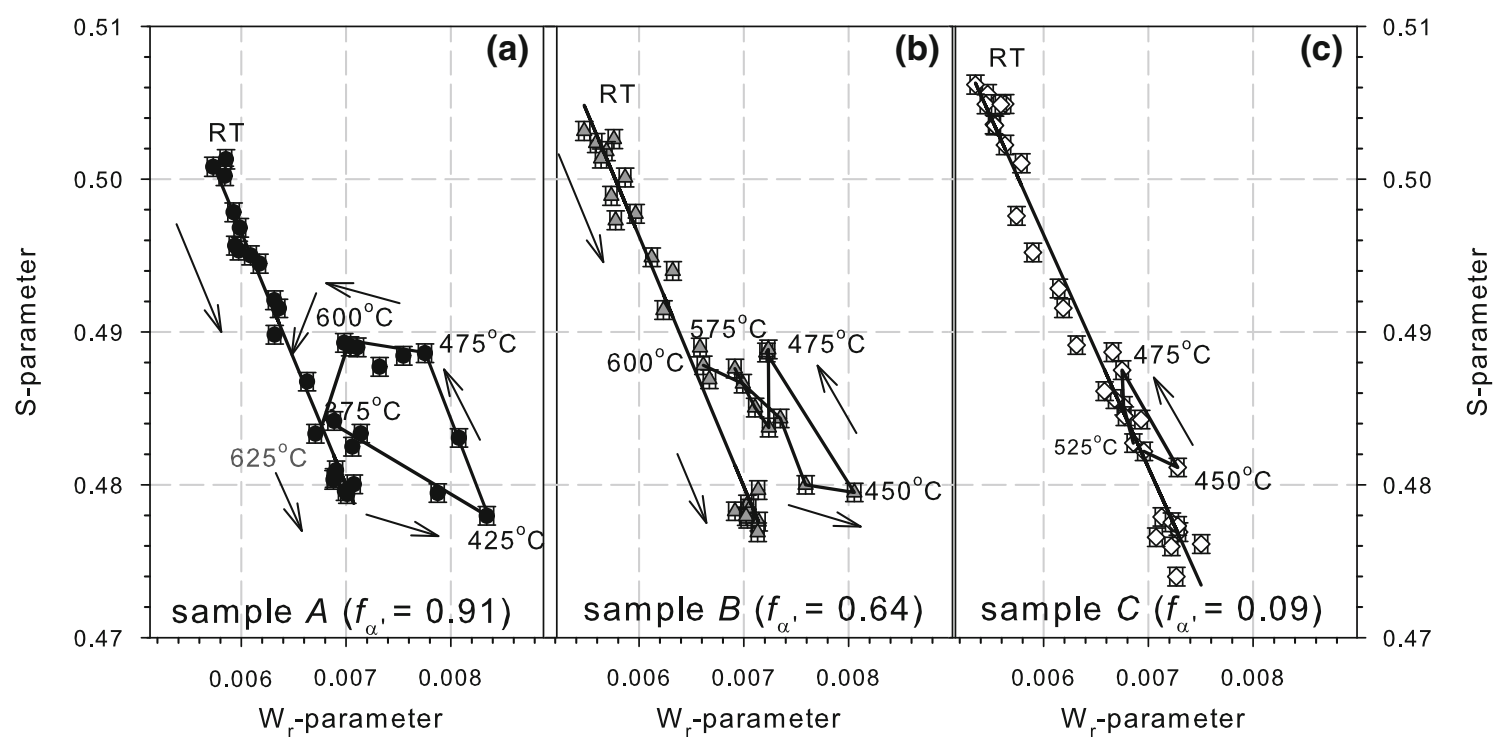

Fig. 5-S- $W_{\mathrm{r}}$ plots for the isochronal annealing of the samples rolled at different temperatures. $(a)$, (b), and (c) The experimental points for samples A, B, and C, respectively. The arrows indicate the succession of the experimental points. Some points are labeled by the annealing temperature values; $f_{\alpha^{\prime}}$ is the initial fraction of $\alpha^{\prime}$-martensite.

Table III. PL Values in Picoseconds Measured for As-Deformed Samples and after Annealing at Selected Temperatures; the Accuracy of the Obtained Values is \pm 1 ps

\begin{tabular}{lccc}
\hline & $\mathrm{A}\left(f_{\alpha^{\prime}}=0.91\right)$ & $\mathrm{B}\left(f_{\alpha^{\prime}}=0.64\right)$ & $\mathrm{C}\left(f_{\alpha^{\prime}}=0.09\right)$ \\
\hline As deformed & 149 & 152 & 155 \\
$350^{\circ} \mathrm{C}$ & 129 & 133 & 135 \\
$500^{\circ} \mathrm{C}$ & 139 & 136 & 130 \\
$800^{\circ} \mathrm{C}$ & 123 & 115 & 114 \\
\hline
\end{tabular}

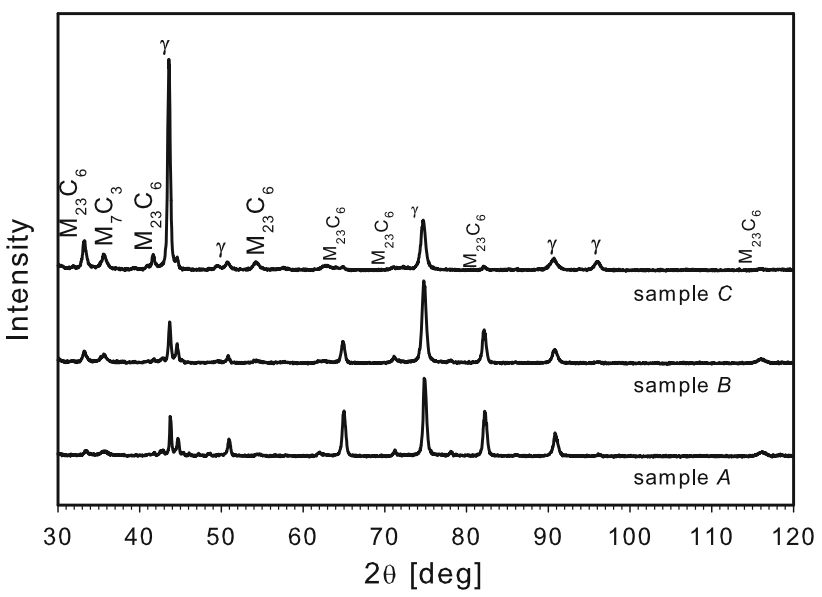

Fig. 6-XRD patterns for the rolled samples A, B, and $\mathrm{C}$ after annealing at $550{ }^{\circ} \mathrm{C}$ for $670 \mathrm{ks}$.

$-17.1 \pm 0.5$ is similar to those obtained for isochronal annealing. For annealing at $550{ }^{\circ} \mathrm{C}$, the straight line in the $S$ - $W_{\mathrm{r}}$ plot fitted for sample $\mathrm{C}$ has a slope equal to $-16.5 \pm 0.9$ (Figure $8(d)$ ). The experimental points for samples A and B diverge from the straight line, as it takes place for isochronal annealing.

\section{DISCUSSION}

Annealing of cold-worked austenitic SS may involve complex microstructural processes such as martensite reversion, precipitation, recovery, recrystallization, and grain growth. Bearing this in mind, the obtained results can be explained as follows.

\section{A. Isochronal Annealing}

Figure 4(a) indicates a softening of the material caused by $\alpha^{\prime}$-martensite reversion for temperatures above $475^{\circ} \mathrm{C}$ in samples $\mathrm{A}$ and $\mathrm{B}$. For sample $\mathrm{C}$, with a lower amount of $\alpha^{\prime}$-martensite, a decrease in the microhardness above $700{ }^{\circ} \mathrm{C}$ follows the values for samples A and B. It is caused by recrystallization. ${ }^{[21]}$ Optical micrographs in the Figure 4 inserts show that after annealing at $750{ }^{\circ} \mathrm{C}$, sample $\mathrm{C}$ was completely recrystallized, while after annealing at $550{ }^{\circ} \mathrm{C}$, its microstructure did not differ significantly from the initial microstructure. Cios et al. showed that the completely recrystallized material does not contain DIM. ${ }^{[22]}$

An increase in the $S$ parameter at $475{ }^{\circ} \mathrm{C}$ coincides with the small maximum of microhardness for samples $\mathrm{A}$ and $\mathrm{B}$ with a higher amount of $\alpha^{\prime}$-martensite. The increase in microhardness may be caused by precipitation of carbides. Carbide precipitation in austenitic SS at approximately $500{ }^{\circ} \mathrm{C}$ is known to be responsible for steel's sensitization to intergranular corrosion. However, at temperatures lower than $450{ }^{\circ} \mathrm{C}$, the rate of $\mathrm{Cr}$ diffusion is slow and the $\mathrm{Cr}$ content of $\mathrm{M}_{23} \mathrm{C}_{6}$ carbides decreases with the decreasing sensitization temperature. 


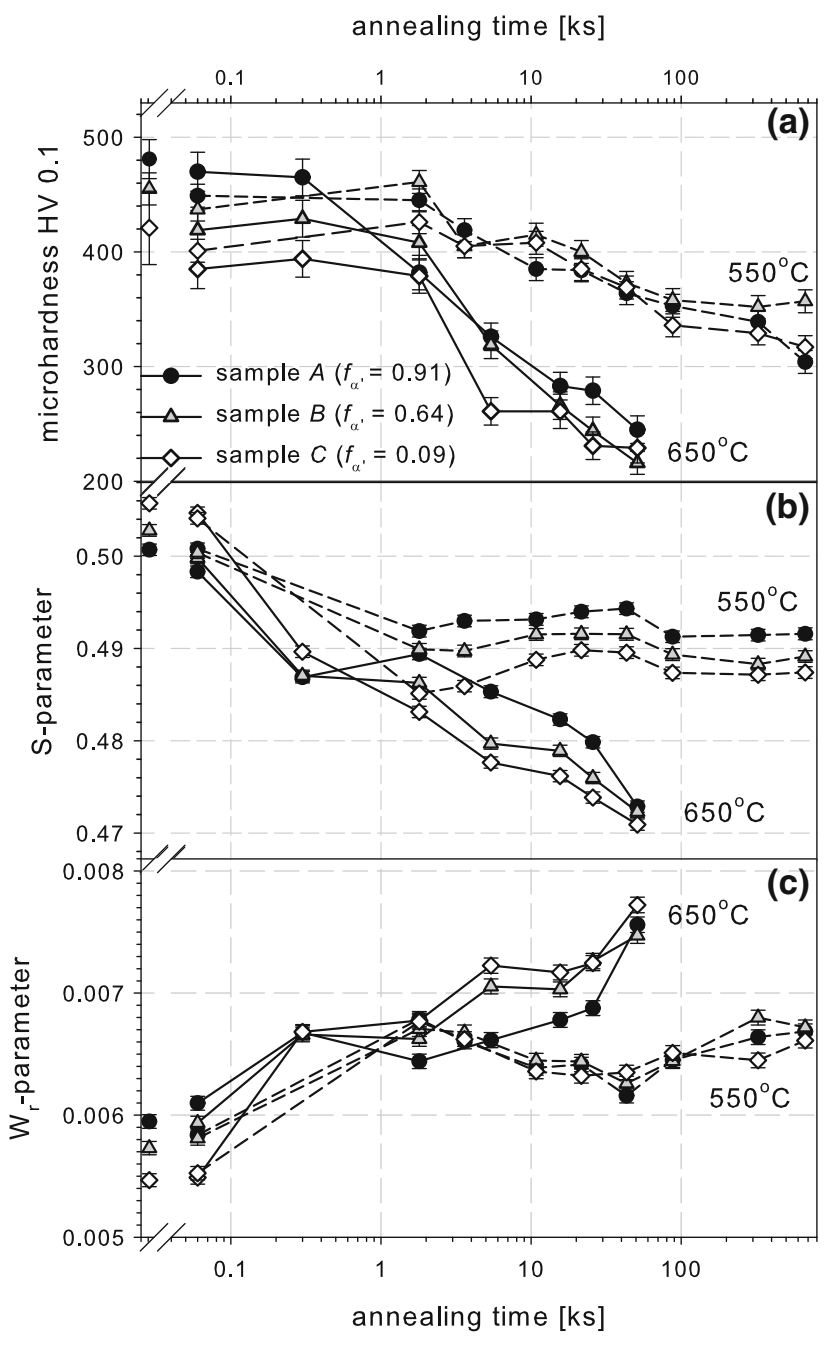

Fig. 7-Effect of the annealing time at $650{ }^{\circ} \mathrm{C}$ and $550{ }^{\circ} \mathrm{C}$ on $(a)$ the microhardness and the values of the (b) $S$ and (c) $W_{\mathrm{r}}$ parameters and, respectively, for samples $\mathrm{A}, \mathrm{B}$, and $\mathrm{C}$ rolled at different temperatures; $f_{\alpha^{\prime}}$ is the initial fraction of $\alpha^{\prime}$-martensite.

The carbides that precipitate during low-temperature aging have a composition that approaches the matrix composition. ${ }^{[23]}$

When considering an increase in the microhardness at $475{ }^{\circ} \mathrm{C}$ for samples $\mathrm{A}$ and $\mathrm{B}$, one can speculate that it may have been caused by an increase in the volume fraction of $\alpha^{\prime}$-martensite. The anomalous evolution of deformation-induced $\alpha^{\prime}$-martensite, i.e., an increase in its volume fraction was reported for isothermal annealing, however, performed at slightly lower temperatures, i.e., from $300{ }^{\circ} \mathrm{C}$ to $400{ }^{\circ} \mathrm{C} .{ }^{[24,25]}$ One of the explanations for this phenomenon also takes into account the precipitation of carbides. This leads to composition inhomogeneities that locally increase $M_{S}$ in the regions depleted of alloying elements, causing the formation of more martensite on cooling. ${ }^{[24]}$

Precipitation of carbides was proposed as an explanation of an increase and subsequent decrease in the $S$ parameter or mean PL values with increasing annealing temperature. ${ }^{[17]}$ The effect was reported for Ti-doped austenitic SS. ${ }^{[26,27]}$ This behavior was attributed to trapping of positrons in misfit dislocations at precipitate-matrix interfaces, more so as $\mathrm{TiC}$ precipitates inside grains. The increasing number of precipitates causes an increase in the $S$ parameter or mean PL value. The growth and coarsening of precipitates reduce the number density of precipitates and decrease the $S$ parameter as well as the mean positron lifetime. Similar behavior was also observed for the annealing of electron-irradiated, deformed, or sensitized Type 304 austenitic SS by Yabuuchi et al. and was attributed to the formation of metal carbide precipitates $\mathrm{M}_{23} \mathrm{C}_{6} \cdot{ }^{[19]} \mathrm{In}$ the case of not-deformed samples, the increase in the $S$ parameter was explained by the Kirkendall effect rather than by positron trapping in the misfit dislocations at the $\mathrm{M}_{23} \mathrm{C}_{6}$ precipitate interface. This explanation is based on the fact that if grains are large, nearly all positrons annihilate inside the grains. The probability of positrons being trapped in the misfit dislocations at the precipitate interface at grain boundaries should be low. Additionally, migration of $\mathrm{Cr}$ atoms to grain boundaries results in a flow of vacancies into the grains. The quenching of samples after annealing should retain the vacancies as positron trapping sites. However, this effect cannot be used for the explanation of the results presented in this article because the samples were slowly cooled after each annealing step, which should have caused the removal of vacancies. Vacancy defects inside precipitates were also suggested as possible candidates for positron trapping sites. ${ }^{[11]}$

It is known that cold working accelerates the precipitation of both carbides and intermetallic phases in $\mathrm{SS}^{[27,29]}$ When deformation-induced $\alpha^{\prime}$-martensite is present, the interphase boundaries arising as a result of its reversion are the sites of $\mathrm{M}_{23} \mathrm{C}_{6}$ nucleation and growth. ${ }^{[2]}$ In our case, it should be noted that the higher the $\alpha^{\prime}$-martensite volume fraction, the higher the values of the $S$ parameter in the temperature range from $475{ }^{\circ} \mathrm{C}$ to $600{ }^{\circ} \mathrm{C}$, in spite of the lower deformation degree (Figure 4 (b)). This behavior indicates the influence of the initial $\alpha^{\prime}$-martensite volume fraction on the formation of positron trapping defects. The reversion of $\alpha^{\prime}$-martensite provides sites for metal carbide nucleation, whereas volume excess resulting from the bcc/fcc change may contribute to an excess of vacancy-type defects at the interphase boundaries.

The influence of the initial $\alpha^{\prime}$-martensite fraction is visible for the $W_{\mathrm{r}}$ parameter in the region of its maximum (Figure 4(c)). Moreover, the $S$ - $\mathrm{W}_{\mathrm{r}}$ plot indicates changes in the chemical surrounding of the sites of positron annihilation, which are more pronounced for samples A and B with a higher $\alpha^{\prime}$-martensite fraction. The divergence of the experimental points from the straight line in the $S-W_{\mathrm{r}}$ plot already starts at $375^{\circ} \mathrm{C}$ (Figure 5(a)). The changes continue (the experimental points form a loop), and this behavior is reflected in an increase and subsequent decrease in the concentration of defects with a chemical surrounding different from that introduced by plastic deformation. Moreover, this chemical surrounding also evolves with altering carbide composition, i.e., $\mathrm{Fe}$ and $\mathrm{Cr}$ content of $\mathrm{M}_{23} \mathrm{C}_{6}$ carbides precipitating during annealing at increasingly higher temperatures. The decrease in the $W_{\mathrm{r}}$-parameter value 


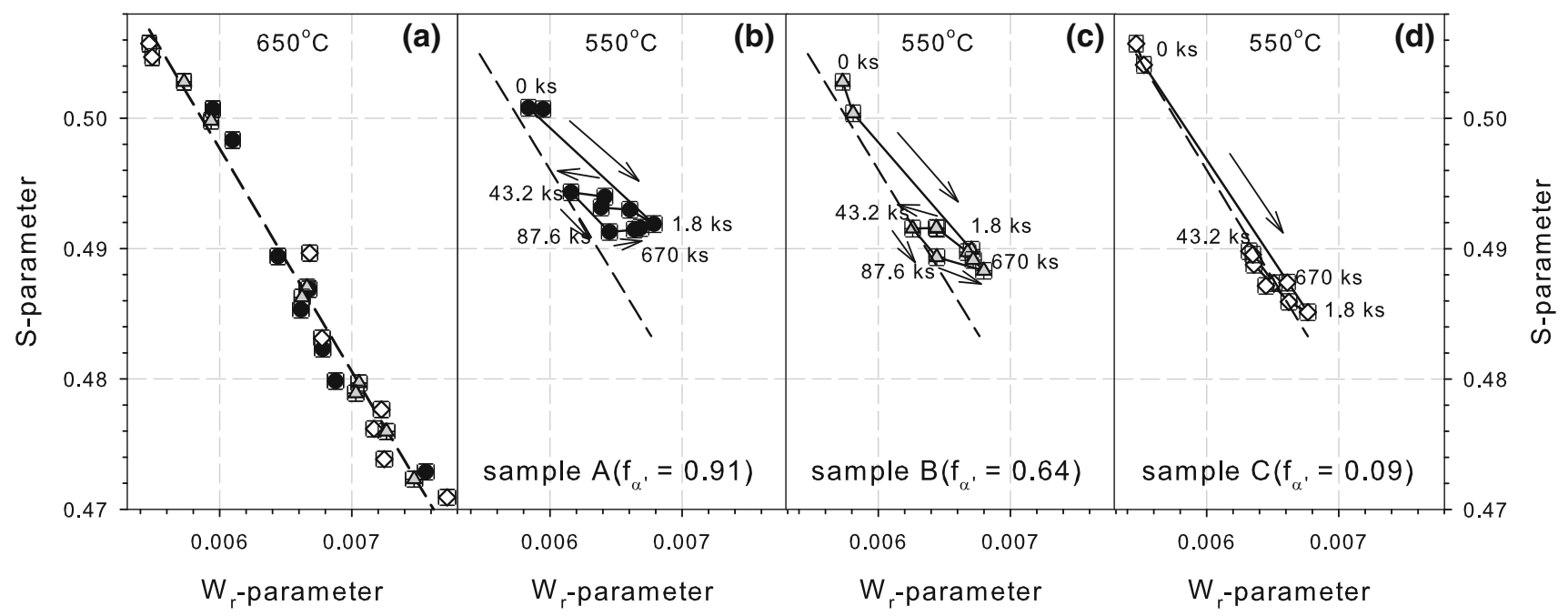

Fig. 8-S- $W_{\mathrm{r}}$ plots for the isothermal annealing of samples A, B, and C rolled at different temperatures; $f_{\alpha^{\prime}}$ is the initial fraction of $\alpha^{\prime}$-martensite. (a) The plot for annealing at $650{ }^{\circ} \mathrm{C}$ contains the experimental points for all three samples. The symbols for the individual samples are the same as when annealed at $550^{\circ} \mathrm{C}$. The dashed straight line is fitted to all the points. $(b),(c)$, and $(d)$ The experimental points for samples A, B, and C, respectively, isothermally annealed at $550{ }^{\circ} \mathrm{C}$. The dashed straight line is fitted to the data for sample C. The arrows indicate the succession of the experimental points. Some points are labeled by the annealing time values.

for temperatures from $425^{\circ} \mathrm{C}$ to $625^{\circ} \mathrm{C}$ may be caused by the influence of annihilation with core electrons of carbon since the coincidence DB spectrum for graphite has much lower values for core electron annihilation energies than those for steel, as observed by Rajaraman et al. ${ }^{[27]}$

Our previous studies of martensite reversion in 1.4307 SS deformed in uniaxial tension revealed the presence of clusters of six to nine vacancies for the sample deformed at LN temperature to 5 pct elongation with the $\alpha^{\prime}$-martensite volume fraction of 0.25 . For the sample deformed to $32 \mathrm{pct}$ elongation with the $\alpha^{\prime}$-martensite volume fraction of 0.19 , the vacancy clusters, if present, were smaller and had a lower concentration. ${ }^{[10]}$ The PL spectra measured for the rolled samples after annealing at $500{ }^{\circ} \mathrm{C}$, in the region of the higher $S$-parameter values, i.e., a step in Figure 4(b), exhibit only one component, which can be treated as the mean positron lifetime, i.e., 139, 136, and 130 ps for samples A, B, and $\mathrm{C}$, respectively. If the differences in the deformation mode can be neglected, the results for the tension-deformed samples and the lack of evidence of vacancy clusters for the rolled samples seem to indicate that the conditions favorable for vacancy cluster formation are the following: a relatively high initial $\alpha^{\prime}$-martensite volume fraction and a low degree of deformation.

\section{B. Isothermal Annealing}

The linear relationship of the experimental points in Figure 8(a) for all three samples annealed at $650{ }^{\circ} \mathrm{C}$ suggests no noticeable change in the type of positron trapping sites. However, there are differences between the samples in the $S$ - and $W_{\mathrm{r}}$-parameter dependences due to an $\alpha^{\prime}$-martensite volume fraction. For samples with higher $\alpha^{\prime}$-martensite volume fractions, the higher value of the $S$ parameter for an annealing time from 1.8 to $25.8 \mathrm{ks}$ indicates higher concentrations of defects (Figure 7(b)). These differences disappear after annealing for $51 \mathrm{ks}$. A similar influence of the $\alpha^{\prime}$-martensite fraction can be seen for samples annealed at $550{ }^{\circ} \mathrm{C}$, and it does not change when annealing time is increased. A closer inspection of the $S$ - $W_{\mathrm{r}}$ plots for samples isochronally annealed at $550{ }^{\circ} \mathrm{C}$ reveals that the experimental points for samples B and C diverge from the straight line fitted for sample A. Then they converge for the annealing time of $43.1 \mathrm{ks}$, for which there is a local maximum of the $S$-parameter value. This effect can be explained by the nucleation and then coarsening of carbide precipitates, the presence of which was confirmed by XRD patterns (Figure 6). For longer annealing times, the points diverge again from the straight line. This behavior, which starts at $87.6 \mathrm{ks}$, indicates a subsequent alteration of positron trapping sites, which can be connected to the early stages of intermetallic phase precipitation.

\section{CONCLUSIONS}

The PAS application to the study of the annealing behavior of rolled metastable SS 1.4307 with different amounts of deformation-induced $\alpha^{\prime}$-martensite yields valuable information. The main results can be summarized as follows.

1. The first stage of recovery indicated by a decrease in the $S$ parameter for isochronal annealing in the temperature range between $200{ }^{\circ} \mathrm{C}$ and $425^{\circ} \mathrm{C}$ results in annealing of vacancies induced by plastic deformation.

2. The reverse transformation of $\alpha^{\prime}$-martensite in the temperature range between $475^{\circ} \mathrm{C}$ and $600{ }^{\circ} \mathrm{C}$ indicated by a decrease in microhardness is accompanied by the generation of new positron trapping 
defects with a different chemical surrounding from those induced initially by rolling.

3. The initial $\alpha^{\prime}$-martensite volume fraction influences the formation of these defects.

4. The various chemical surroundings of the positron trapping defects indicate that they are misfit dislocations at the interface of metal carbide precipitates nucleating at defects generated by $\alpha^{\prime}$-martensite reversion.

\section{OPEN ACCESS}

This article is distributed under the terms of the Creative Commons Attribution 4.0 International License (http://creativecommons.org/licenses/by/4.0/), which permits unrestricted use, distribution, and reproduction in any medium, provided you give appropriate credit to the original author(s) and the source, provide a link to the Creative Commons license, and indicate if changes were made.

\section{REFERENCES}

1. R. Fawley, M.A. Quader, and R.A. Dodd: Trans. TMS-AIME, 1968, vol. 242, pp. 771-76.

2. R.E. Schramm and R.P. Reed: Metall. Trans. A, 1975, vol. 6A, pp. $1345-51$.

3. P.L. Mangonon, Jr and G. Thomas: Metall. Trans., 1970, vol. 1, pp. $1577-86$.

4. V. Seetharaman and R. Krishnan: J. Mater. Sci., 1981, vol. 16, pp. $523-30$.

5. J. Singh: J. Mater. Sci., 1985, vol. 20, pp. 3157-66.

6. A.F. Padilha, R.L. Plaut, and P.R. Rios: ISIJ Int., 2003, vol. 43, pp. $135-43$.

7. R. Krause-Rehberg and H.S. Leipner: Solid-State Sciences, Springer, Berlin, 1999, vol. 127.
8. E. Dryzek, M. Sarnek, and K. Siemek: Nukleonika, 2013, vol. 58, pp. 213-17.

9. E. Dryzek and M. Sarnek: Acta Phys. Polon. A, 2014, vol. 125, pp. 710-13.

10. E. Dryzek, M. Sarnek, and M. Wróbel: J. Mater. Sci., 2014, vol. 49 , pp. 8449-58.

11. S. Hari Babu, G. Amarendra, R. Rajaraman, and C.S. Sundar: $J$. Phys.: Conf. Ser., 2013, vol. 443, p. 012010.

12. A.S. Lima and A.M. Nascimento: J. Mater. Sci., 2005, vol. 40, pp. 139-44.

13. M. Shirdel, H. Mirzadeh, and M.H. Parsa: Mater. Sci. Eng. A, 2015, vol. 624 , pp. $256-60$

14. ISO 4545:1:2017: "Metallic Materials -Knoop Hardness Test Part 1: Test Method.".

15. http://www.ifj.edu.pl/private/jdryzek/page_r18.html. Accessed Feb. 20, 2018.

16. J. Kansy: Nucl. Instr. Meth. A, 1996, vol. 374, pp. 235-44.

17. J. Dryzek, C. Wesseling, E. Dryzek, and B. Cleff: Mater. Lett., 1994, vol. 21, pp. 209-14.

18. U. Holzwarth, A. Barbieri, S. Hansen-Ilzhöfer, P. Schaaff, and M. Haaks: Appl. Phys. A, 2001, vol. 73, pp. 467-75.

19. A. Yabuuchi, M. Maekawa, and A. Kawasuso: J. Nucl. Mater., 2011, vol. 419, pp. 9-14.

20. M.F. McGuire: Stainless Steels for Design Engineers, ASM International, Materials Park, OH, 2008.

21. L.F.M. Martins, R.L. Plaut, and A.F. Padilha: ISIJ Int., 1998, vol. 38 , pp. $572-79$.

22. G. Cios, T. Tokarski, A. Żywczak, R. Dziurka, M. Stępień, Ł. Gondek, M. Marciszko, B. Pawłowski, K. Wieczerzak, and P. Bała: Metall. Mater. Trans. A, 2018, vol. 48A, pp. 4999-5008.

23. C.G. Schmidt, R.D. Caligiuri, L.E. Eiselstein, S.S. Wing, and D. Cubicciotti: Metall. Trans. A, 1987, vol. 18A, pp. 1483-93.

24. F. Gauzzi, R. Montanari, G. Principi, and M.E. Tata: Mater. Sci. Eng. A, 2006, vols. 438-440, pp. 202-06.

25. S.S.M. Tavares, D. Fruchart, and S. Miraglia: J. Alloys Compd., 2000, vol. 307, pp. 311-17.

26. J. Arunkumar, S. Abhaya, R. Rajaraman, G. Amarendra, K.G.M. Nair, C.S. Sundar, and R. Baldev: J. Nucl. Mater., 2009, vol. 384, pp. 245-48.

27. R. Rajaraman, G. Amarendra, and C.S. Sundar: Phys. Status Solidi $C$, 2009, vol. 6, pp. 2285-90.

28. E.A. Trillo, R. Beltran, J.G. Maldonado, R.J. Romero, L.E. Murr, W.W. Fisher, and A.H. Advani: Mater. Charact., 1995, vol. 35 , pp. $99-112$.

29. Y.J. Oh and J.H. Hong: J. Nucl. Mater., 2000, vol. 278, pp. $242-50$. 